\title{
Enhancement of methane production from long chain fatty acid based effluents
}

\author{
A.J. Cavaleiro, M.A. Pereira, M. Alves * \\ IBB - Institute for Biotechnology and Bioengineering, Centre of Biological Engineering, University of Minho, Campus de Gualtar, $4710-057$ Braga, Portugal
}

Received 1 May 2007; received in revised form 2 September 2007; accepted 4 September 2007

Available online 19 November 2007

\begin{abstract}
Two anaerobic sludges previously loaded with oleate and palmitate accumulated $4570 \pm 257$ and $5200 \pm 9$ mgCOD-LCFA gVSS ${ }^{-1}$, respectively. These sludges were incubated in batch assays and methane production was recorded after addition of $100-900 \mathrm{mg} \mathrm{L}^{-1}$ of oleate and palmitate, respectively. The batch assays were conducted before and after allowing the depletion of the biomass-associated LCFA. The presence of biomass-associated LCFA decreased the capacity of both sludges to convert the added LCFA to methane. After the degradation of biomass-associated LCFA, the lag phases observed before the onset of methane production were significantly reduced, evidencing an increase in the tolerance of the acetotrophic methanogens to the presence of LCFA. In another experiment, three recurrent pulses were performed with a real dairy wastewater containing $3.6 \mathrm{gCOD} \mathrm{L}^{-1}$, from which $53 \%$ was fat. Methane yields of $0.45 \pm 0.01,0.88 \pm 0.02$ and $1.29 \pm 0.08 \mathrm{gCOD}-\mathrm{CH}_{4} \mathrm{gCOD}_{\text {fed }}^{-1}$ were achieved in the first, second and third pulses, respectively, evidencing an increasing capacity of the sludge to convert substrate accumulated in previous additions.

(C) 2007 Elsevier Ltd. All rights reserved.
\end{abstract}

Keywords: Oleic acid; Palmitic acid; Anaerobic biodegradation; Pulse feeding; Dairy wastewater

\section{Introduction}

Lipids are a group of organic pollutants whose conversion into biogas has been considered very difficult. Characterized either as fats or oils and greases, the lipids are one of the major components of organic matter in wastes and wastewaters such as those coming from food processing industries, slaughterhouses, dairy industries and fat refineries ( $\mathrm{Li}$ et al., 2002). These compounds are glycerol bonded to LCFA, alcohols, and other groups by an ester or ether linkage. Triacylglycerides, also called neutral fats, are the most abundant family of lipids and are hydrolyzed by extracellular lipases to yield glycerol and LCFA. Glycerol is further degraded via acidogenesis while LCFA are degraded to acetate, $\mathrm{H}_{2}$ and $\mathrm{CO}_{2}$ through the $\beta$-oxidation process (syntrophic acetogenesis) (Stryer, 1995).

\footnotetext{
* Corresponding author. Tel.: +351 253604 400; fax: +351 253678986. E-mail address: madalena.alves@deb.uminho.pt (M. Alves).
}

Theoretically $1.01 \mathrm{~L}$ of methane at standard temperature and pressure (STP) can be produced from for instance $1 \mathrm{~g}$ of oleate (unsaturated LCFA, C18:1), whereas only $0.37 \mathrm{~L}$ can be produced from $1 \mathrm{~g}$ of glucose. Therefore, wastes or wastewaters with a high lipid-content represent an attractive source for methane production (Kim et al., 2004). This potential is however limited due to operational problems. Diverse technologies applied to the anaerobic treatment of oily effluents are reported in the literature, but information available is not always complete (Table 1). For instance, the methane yield and effluent VSS are most of times omitted. It can be observed that these systems do not always accomplish a desirable performance in terms of COD conversion to methane, and reports of reactors' failure are quite frequent. In this way, the treatment of these types of wastewaters is still a challenge, continuously driven by emergent practical and fundamental knowledge (Sousa, 2007).

One of the most reported problems of high rate anaerobic reactor technology such as the upflow anaerobic sludge 
Table 1

Treatment of wastewater containing lipids and LCFA in different anaerobic reactors (adapted from Sousa, 2007)

\begin{tabular}{|c|c|c|c|c|c|c|}
\hline Type of wastewater & Type of reactor & $\operatorname{HRT}(\mathrm{d})$ & $\begin{array}{l}\text { OLR } \\
\left(\mathrm{gCOD} \mathrm{L}^{-1} \mathrm{~d}^{-1}\right)\end{array}$ & $\begin{array}{l}\text { COD removal } \\
(\%)\end{array}$ & $\begin{array}{l}\mathrm{CH}_{4} \text { yield } \\
\left(\mathrm{LCH}_{4} \mathrm{gCOD}^{-1}\right)\end{array}$ & Reference \\
\hline LCFA mixture & UASB & $0.7-1.2$ & $3.2-9.4$ & $82-93$ & ND & Hwu et al. (1998) \\
\hline LCFA mixture (+glucose) & $\mathrm{CSTR}+\mathrm{UASB}$ & 2.9 & $0.2-2.7$ & $60-95$ & ND & Kim et al. (2004) \\
\hline Oleate $(+$ skim milk $)$ & EGSB & 1 & 4-8 & $69-97$ & $0.03-0.28$ & Pereira et al. (2002a) \\
\hline Oleate (+skim milk) & $\mathrm{AF}$ & $3.3-0.64$ & $0.7-12.5$ & $80-95$ & $0.09-0.36$ & \\
\hline $\begin{array}{l}\text { Saccharose }+ \text { oleate or } \\
\text { Saccharose }+ \text { stearate }\end{array}$ & UASB or DAEB & 1 & $4.2-6.4$ & $76-93$ & ND & Miranda et al. (2006) \\
\hline Dairy wastewater & IFB or ITB & $63.6-3$ & $0.5-10$ & $75-98$ & ND & Arnaiz et al. (2003) \\
\hline Dairy wastewater & BFBR & $0.3-0.5$ & 10 (up to) & $85-90$ & Approx. 0.37 & Haridas et al. (2005) \\
\hline \multirow[t]{4}{*}{ Ice-cream factory wastewater } & $\mathrm{AF}$ & 0.9 & 6.4 & 67 & 0.36 & Hawkes et al. (1995) \\
\hline & Contact process & 5.5 & 1.1 & 82 & 0.39 & \\
\hline & FBR & 1.5 & 4.2 & 56 & 0.37 & \\
\hline & UASB & 1.6 & 2.2 & 49 & 0.19 & \\
\hline Food industry wastewater & UASB & $5-1.25$ & $1.3-8$ & $84-98$ & $0.18-0.48$ & Jeganathan et al. (2006) \\
\hline Slaughterhouse wastewater & EGSB & 0.2 & 15 (up to) & 70 & ND & Núnez and Martínez (1999) \\
\hline Slaughterhouse wastewater & ASBR & 2.9 & $31.3^{\mathrm{a}}$ & 94 & ND & Masse et al. (2002) \\
\hline Slaughterhouse wastewater & UASB & $0.3-0.1$ & $13-30$ & $60-93$ & $0.20-0.28$ & Torkian et al. (2003) \\
\hline Palm oil mill wastewater & MABR & $3-10$ & $1.6-5.3$ & $87-95$ & $0.32-0.42$ & Faisal and Unno (2001) \\
\hline $\begin{array}{l}\text { Sunflower oil factory } \\
\text { wastewater }\end{array}$ & UASB & $2-2.8$ & $1.6-7.8$ & 87 & $0.16-0.35$ & Saatci et al. (2003) \\
\hline
\end{tabular}

COD, chemical oxygen demand; HRT, hydraulic retention time; OLR, organic loading rate; UASB, upflow anaerobic sludge blanket; CSTR, continuous stirred tank reactor; EGSB, expanded granular sludge bed; AF, anaerobic filter; IFB, inverse fluidised bed; ITB, inverse turbulent reactor; DAEB, downflow anaerobic expanded bed; BFBR, buoyant filter bioreactor; FBR, fluidised bed reactor; ASBR, anaerobic sequencing batch reactor; MABR, modified anaerobic baffled reactor; ND, not determined.

${ }^{\text {a }}$ Calculated on the basis of $1 \mathrm{~h}$ feeding (subsequent reaction and settling phases lasted $69 \mathrm{~h}$ ).

blanket (UASB) or the expanded granular sludge bed (EGSB) reactors, is the adsorption of LCFA that induces sludge disintegration, flotation and washout (Amaral et al., 2004). Also transport limitation phenomena, caused by LCFA accumulation onto the sludge, were found to have an important contribution to the observed lag phases preceding methane production, generally reported to be ascribed to mechanisms of cell wall damage or to long term acclimation (Pereira et al., 2005). It was found that the observed temporary decrease in the methanogenic activity after the contact with LCFA is a reversible phenomenon, being eliminated after the conversion to methane of the biomass-associated LCFA (Pereira et al., 2002a, 2004, 2005), suggesting that sequencing accumulation/degradation steps could promote a sustainable biogas production from LCFA.

Recently, Nielsen and Ahring (2006) also showed that the addition of oleate pulses to thermophilic reactors treating mixtures of cattle and pig manure had a stimulating effect on the overall process. Successful co-digestion of different types of waste with lipids, added in a discontinuous way, is a common practice in many full scale biogas plants. However, this addition is usually made empirically, causing, in some cases process failure. The dynamics of the LCFA accumulation, the maximum amount of lipids that can be added and the frequency of additions are some aspects that require further study.

In this work some further insights on the role of LCFA accumulation onto the sludge in the methane production course are presented. Two sets of experiments were designed. In experiment I, two sludges loaded with LCFA, obtained after prolonged contact with oleate or palmitate, were used to asses the effect of allowing the depletion of the biomass-associated LCFA prior to a new LCFA pulse, in terms of methane production and LCFA effect towards the acetotrophic methanogens. Palmitate (C16:0) and oleate (C18:1) where used as LCFA models, since they are respectively the most abundant saturated and unsaturated LCFA present in waste/wastewater (Viswanathan et al., 1962; Hanaki et al., 1981; Quéméneur and Marty, 1994).

In experiment II, anaerobic bioconversion to methane of a fat-rich dairy wastewater, using repeated pulse feeding, was assessed in batch assays.

\section{Methods}

Table 2 summarises the conditions used in the two experiments.

\subsection{Experiment I: LCFA biodegradation capacity and effect of LCFA towards the aceticlastic methanogens}

\subsubsection{Sludge source}

Suspended sludge containing biomass-associated LCFA, was obtained after continuous load with oleate (sludge 1) or palmitate (sludge 2) in two $1 \mathrm{~L}$ expanded granular sludge bed (EGSB) reactors seeded with the same inoculum, as described elsewhere (Pereira et al., 2005). When incubated in batch assays both sludges were able to produce methane exclusively from the biomass-associ- 
Table 2

Summary of the conditions used in the two experiments

\begin{tabular}{|c|c|c|c|c|}
\hline & Sludge used & $\begin{array}{l}\text { LCFA accumulated }{ }^{\mathrm{a}} \text { onto } \\
\text { the sludge }\left(\mathrm{mg} \text { COD } \mathrm{gVSS}^{-1}\right)\end{array}$ & $\begin{array}{l}\text { Substrate added in the } \\
\text { batch experiments }\end{array}$ & $\begin{array}{l}\text { Methane production recorded } \\
\text { in batch assays from... }\end{array}$ \\
\hline Experiment 1 & $\begin{array}{l}\text { Acclimated to oleate } \\
\text { (sludge 1) } \\
\text { Acclimated to palmitate } \\
\text { (sludge 2) }\end{array}$ & $\begin{array}{l}4570 \pm 257(83 \% \text { of all } \\
\text { LCFA as palmitate }) \\
5200 \pm 9(100 \% \text { of all } \\
\text { LCFA as palmitate })\end{array}$ & $\begin{array}{l}\text { None } \\
\text { Oleate }\left[0-900 \mathrm{mg} \mathrm{L}^{-1}\right] \\
\text { None } \\
\text { Palmitate }\left[0-900 \mathrm{mg} \mathrm{L}^{-1}\right]\end{array}$ & $\begin{array}{l}\text { Accumulated } \mathrm{LCFA}^{\mathrm{a}} \\
\text { Accumulated } \mathrm{LCFA}^{\mathrm{a}}+\text { added oleate } \\
\text { Accumulated } \mathrm{LCFA}^{\mathrm{a}} \\
\text { Accumulated } \mathrm{LCFA}^{\mathrm{a}}+\text { added } \\
\text { palmitate }\end{array}$ \\
\hline Experiment 2 & $\begin{array}{l}\text { Acclimated to oleate in } \\
\text { sequential feeding mode }\end{array}$ & None & $\begin{array}{l}\text { Real dairy effluent } \\
\text { with } 3.6 \mathrm{~g} \text { COD L } \\
\text { from which } 53 \% \text { was fat }\end{array}$ & $\begin{array}{l}\text { Three repeated pulses of substrate } \\
\text { at a specific load of } 1 \mathrm{~g} \mathrm{COD} \mathrm{gVSS}^{-1}\end{array}$ \\
\hline
\end{tabular}

${ }^{a}$ Accumulation of LCFA by mechanisms of adsorption, precipitation and entrapment. This residual substrate was not removed after two consecutive washings with anaerobic buffer.

ated LCFA and the maximum plateau achieved in the cumulative methane production curves was considered an indirect measurement of the amount of accumulated LCFA. Specific LCFA contents of $4570 \pm 257$ and of $5200 \pm 9 \mathrm{mg} \mathrm{COD} \mathrm{gVSS}^{-1}$ were found to be present in sludges 1 and 2, respectively (Pereira et al., 2005). Palmitic acid was the main LCFA accumulated onto both sludges, representing $83 \%$ of the total LCFA present in sludge 1 and the totality of the LCFA present in sludge 2 (Pereira et al., 2005).

\subsubsection{LCFA biodegradation assays}

The LCFA biodegradation capacity of the sludge before and after degrading the biomass-associated LCFA was compared by performing parallel assays. After it had been washed with anaerobic basal medium and centrifuged twice, the sludge was incubated in $25 \mathrm{~mL}$ vials $\left(12.5 \mathrm{~mL}\right.$ working volume, VSS content around $\left.5 \mathrm{gL}^{-1}\right)$, at $37^{\circ} \mathrm{C}, 150 \mathrm{rpm}$, under strict anaerobic conditions. The basal medium used, made up with demineralized water, was composed of cysteine- $\mathrm{HCl}\left(0.5 \mathrm{~g} \mathrm{~L}^{-1}\right)$ and sodium bicarbonate $\left(3 \mathrm{~g} \mathrm{~L}^{-1}\right)$, the $\mathrm{pH}$ was adjusted to 7.0-7.2 with $\mathrm{NaOH} 8 \mathrm{~N}$ and was prepared under strict anaerobic conditions. No calcium or trace-nutrients were added. Two sets of vials were separated for parallel assays. In the first set, oleate (for sludge 1) or palmitate (for sludge 2) was added to the vials at concentrations ranging from 100 to $900 \mathrm{mg} \mathrm{L}^{-1}$. Composition of the accumulated biogas was assessed periodically as described in Section 2.2.4, and methane production was determined. In the other set of vials, no substrate was added, but the degradation of the biomass-associated LCFA was followed until methane production ceased. These vials were then depressurized, vented with $\mathrm{N}_{2} /$ $\mathrm{CO}_{2}(80: 20 \mathrm{vol} / \mathrm{vol})$, and the capacity of the sludge to degrade the added individual LCFA (oleate for sludge 1 and palmitate for sludge 2 , in the same concentration as before) was measured, as described for the first set of vials. All batch tests were performed in duplicate assays. Methane production values were corrected for standard temperature and pressure conditions (STP) and expressed as $\mathrm{mg} \mathrm{COD}-\mathrm{CH}_{4}$.

\subsubsection{Toxicity tests}

In the toxicity tests, oleate (for sludge 1) and palmitate (for sludge 2) were the potential individual toxicants at concentrations ranging from 100 to $900 \mathrm{mg} \mathrm{L}^{-1}$. Acetate $(30 \mathrm{mM})$ was added, in order to select for the aceticlastic trophic group. The choice of this trophic group for the toxicity studies was based on its generalized higher susceptibility to adverse conditions (Yang and Speece, 1986) and its important metabolic role on the anaerobic digestion process (Gujer and Zehnder, 1983). The individual LCFA concentration that caused a $50 \%$ relative methanogenic aceticlastic activity loss was defined as the toxicity index $\left(\mathrm{IC}_{50}\right)$. The specific methanogenic activity was calculated from the initial slope of the recorded methane production curve. The "toxicity" assessed by this test can also include physical effect of transport limitations as suggested previously (Pereira et al., 2005).

\subsection{Experiment II: repeated pulse feeding of a dairy wastewater in batch assays}

\subsubsection{Sludge source}

The inoculum used in this experiment was composed of non granular anaerobic sludge, previously acclimated to oleate. Biomass acclimation was performed in a sequencing batch reactor fed with a mixture of skim milk and commercial sodium oleate (50:50 in terms of COD), with total concentration increasing from 2 to $40 \mathrm{~g} \mathrm{COD} \mathrm{L}^{-1}$. At this last concentration, skim milk was gradually replaced by sodium oleate, and in the last period this LCFA was the only carbon source fed. Before the batch experiments, this sludge was degassed in order to eliminate the accumulated substrate. For that, biogas production was recorded until an insignificant production was detected.

\subsubsection{Substrate}

The substrate was a real dairy wastewater collected in a small milk processing industrial unit. Total COD was $3.6 \mathrm{~g} \mathrm{~L}^{-1}$, from which $53 \%$ corresponded to fat. A COD/

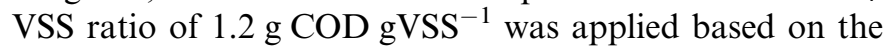
optimum specific LCFA load (that allows a maximum 
methane production rate) previously determined by Pereira et al. (2004).

\subsubsection{Batch experiments}

Experiments were conducted in three sets of vials of $70 \mathrm{~mL}$ prepared with $3 \mathrm{gVSS} \mathrm{L}^{-1}$ of anaerobic sludge and basal medium, similar to the ones previously described for the LCFA biodegradation assays. In each set, two vials were prepared per sampling point for a total of 5 time intervals. In parallel, two vials were set up to measure the biogas production during all the experiment and two others as blank controls for the different pulses. The vials were incubated at $37^{\circ} \mathrm{C}, 150 \mathrm{rpm}$ and strict anaerobic conditions were maintained. Three successive pulses of the dairy wastewater were added on day 0,39 and 81. Each new pulse was added when biogas production from the previous fed stopped. At the different time intervals, two of the vials were sacrificed and the respective content was analyzed for soluble COD and VFA. In parallel the methane production was recorded. Methane production values were corrected for the standard temperature and pressure conditions (STP) and expressed as mg COD- $\mathrm{CH}_{4}$. Background methane production due to residual substrate was recorded but was irrelevant.

\subsubsection{Analytical methods}

Chemical oxygen demand (COD) was determined according to the APHA et al. (1989). The fractions of
COD accumulated onto the sludge and converted to methane were calculated according to Petruy and Lettinga (1997). VFA were determined by HPLC (Jasco, Japan) using a Chrompack column $(6.5 \times 30 \mathrm{~mm})$; the mobile phase was sulfuric acid $(0.01 \mathrm{~N})$ at a flow rate of $0.7 \mathrm{~mL} \min ^{-1}$. The column temperature was set at $60^{\circ} \mathrm{C}$ and the detection was made spectrophotometrically at a wavelength of $210 \mathrm{~nm}$. The methane content of the accumulated biogas was periodically measured by a Pye Unicam GCD gas chromatograph (Cambridge, England) using a Porapack Q (100-180 mesh) column. Helium was used as carrier gas $\left(30 \mathrm{~mL} \mathrm{~min}^{-1}\right)$ and the temperatures of injection port, column and flame ionization detector were 110,35 and $110^{\circ} \mathrm{C}$, respectively.

\section{Results and discussion}

\subsection{Experiment I: $L C F A$ biodegradation capacity and LCFA effect towards the aceticlastic methanogens}

Fig. 1 presents the methane production curves obtained during oleate biodegradation batch experiments exhibited by sludge 1 (fed with oleate), when oleate was added before and after allowing the degradation of the biomass-associated LCFA. It was found that when the biomass-associated LCFA was allowed to be firstly degraded (open circles, Fig. 1), methane production started after $500 \mathrm{~h}$ and total conversion to methane was achieved in the following
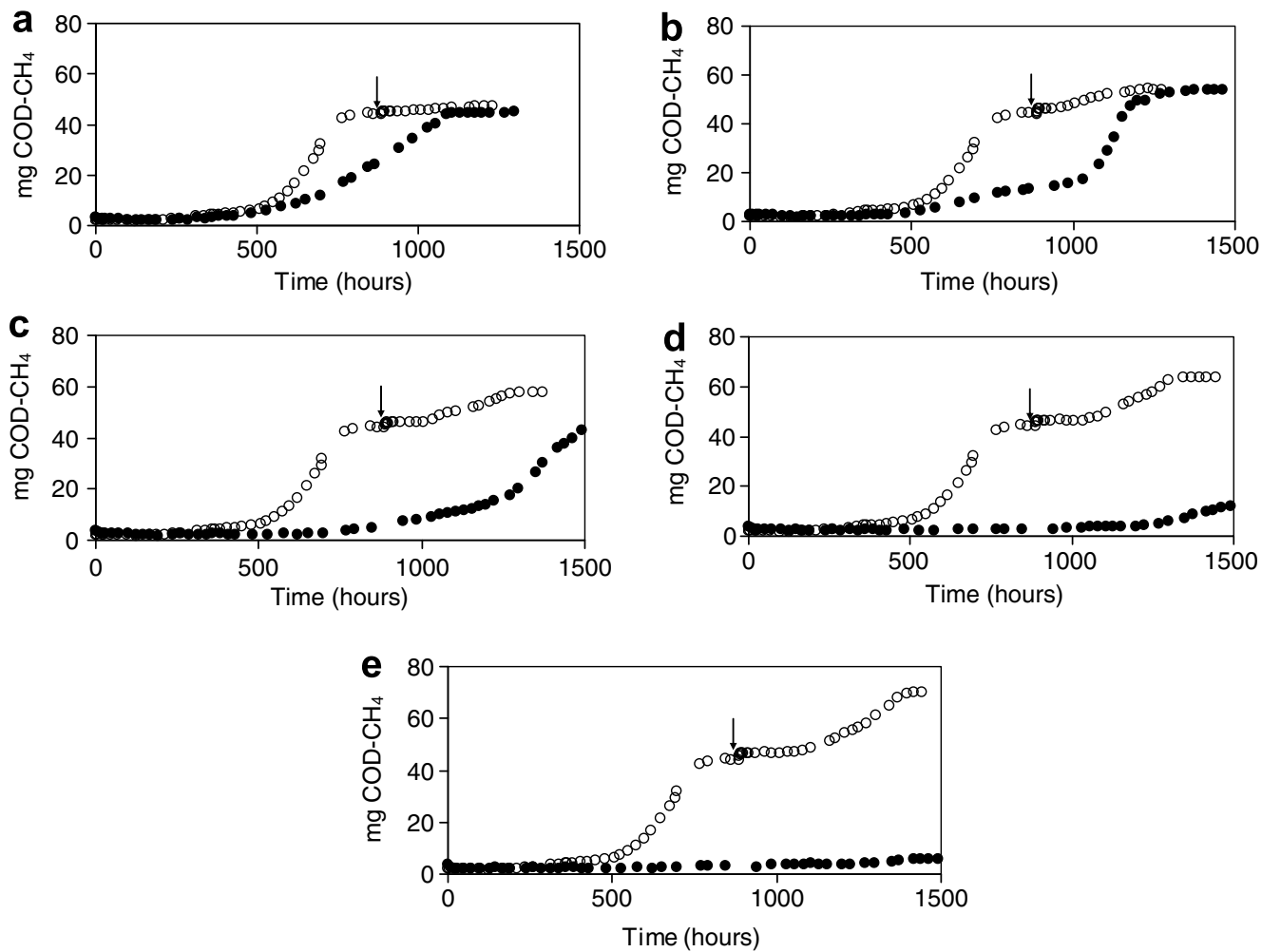

Fig. 1. Methane production during oleate biodegradation batch experiments exhibited by sludge 1, when oleate at concentrations of 100 (a), 300 (b), 500 (c), 700 (d) and 900 (e) $\mathrm{mg} \mathrm{L}^{-1}$, was added before (full circles) and after (open circles) allowing the degradation of the biomass-associated LCFA (arrows indicate moment of oleate addition). Average values are presented and maximum standard deviation was $10 \%$. 
$400 \mathrm{~h}$ ( $900 \mathrm{~h}$ in total). Subsequent added oleate, in concentrations from 100 to $900 \mathrm{mg} \mathrm{L}^{-1}$, was converted to methane in up to $550 \mathrm{~h}$. Conversely, when oleate concentrations between 100 and $900 \mathrm{mg} \mathrm{L}^{-1}$ were added to the sludge containing biomass-associated LCFA (full circles, Fig. 1), an increasing delay on initial methane production up to $1000 \mathrm{~h}$ was observed. For the highest oleate concentration tested, i.e. $900 \mathrm{mg} \mathrm{L}^{-1}$, conversion to methane of the biomass-associated LCFA and subsequent added oleate was achieved in about $1450 \mathrm{~h}$ (open circles, Fig. 1e), whereas no methane was produced during this period of time when oleate was added to the sludge containing biomass-associated LCFA (full circles, Fig. 1e). The results obtained therefore evidence that methane production is significantly enhanced by first allowing the degradation of the biomass-associated LCFA. In these experiments, a considerable lag phase $(500 \mathrm{~h})$ was found to precede the initial methane production from the degradation of the biomass-associated LCFA, however, this fact can be overcome when avoiding excessive accumulation of LCFA into the sludge and, thus, the time required for degradation lowered. The kinetics of mineralization of the LCFA associated to the sludge was previously established and a specific content of about $1000 \mathrm{mg}$ CODLCFA $\mathrm{gVSS}^{-1}$ was found to be the optimal for an efficient methane production rate and no lag phase observed (Pereira et al., 2004). The sludge used in this experiment represents a situation of severe LCFA load, contained a specific LCFA content associated to the biomass 4 fold

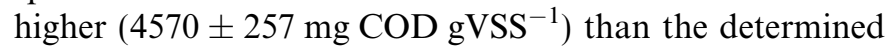
optimum value.

Fig. 2 presents the methane production curves obtained during palmitate biodegradation batch experiments exhibited by sludge 2 (fed with palmitate), when palmitate was added before and after allowing the degradation of the biomass-associated LCFA. As for sludge 1, also the results obtained for sludge 2 evidenced the advantage of allowing the degradation of the LCFA accumulated onto the sludge, prior to a new LCFA addition. A similar effect to that previously observed when the added substrate was oleate, i.e. an increasing delay on initial methane production, was found when adding palmitate concentrations between 100 and $900 \mathrm{mg} \mathrm{L}^{-1}$ to the sludge containing biomass-associated LCFA (full circles, Fig. 2), although less pronounced. The biomass-associated LCFA in sludge 2 was palmitate, which accumulated onto the sludge during the previous continuous feeding with this LCFA, in EGSB reactor. Thus, the observed decreased on methane production caused by the addition of palmitate to sludge 2 presents the effect of adding palmitate on the conversion to methane of the biomass-associated palmitate. In sludge 1, palmitate represented $83 \%$ of the total biomass-associated LCFA that accumulated onto the sludge during the previous continuous feeding with oleate, in EGSB reactor (Pereira et al., 2005), and therefore, the results obtained with this sludge (Fig. 1) present the effect of adding oleate on the
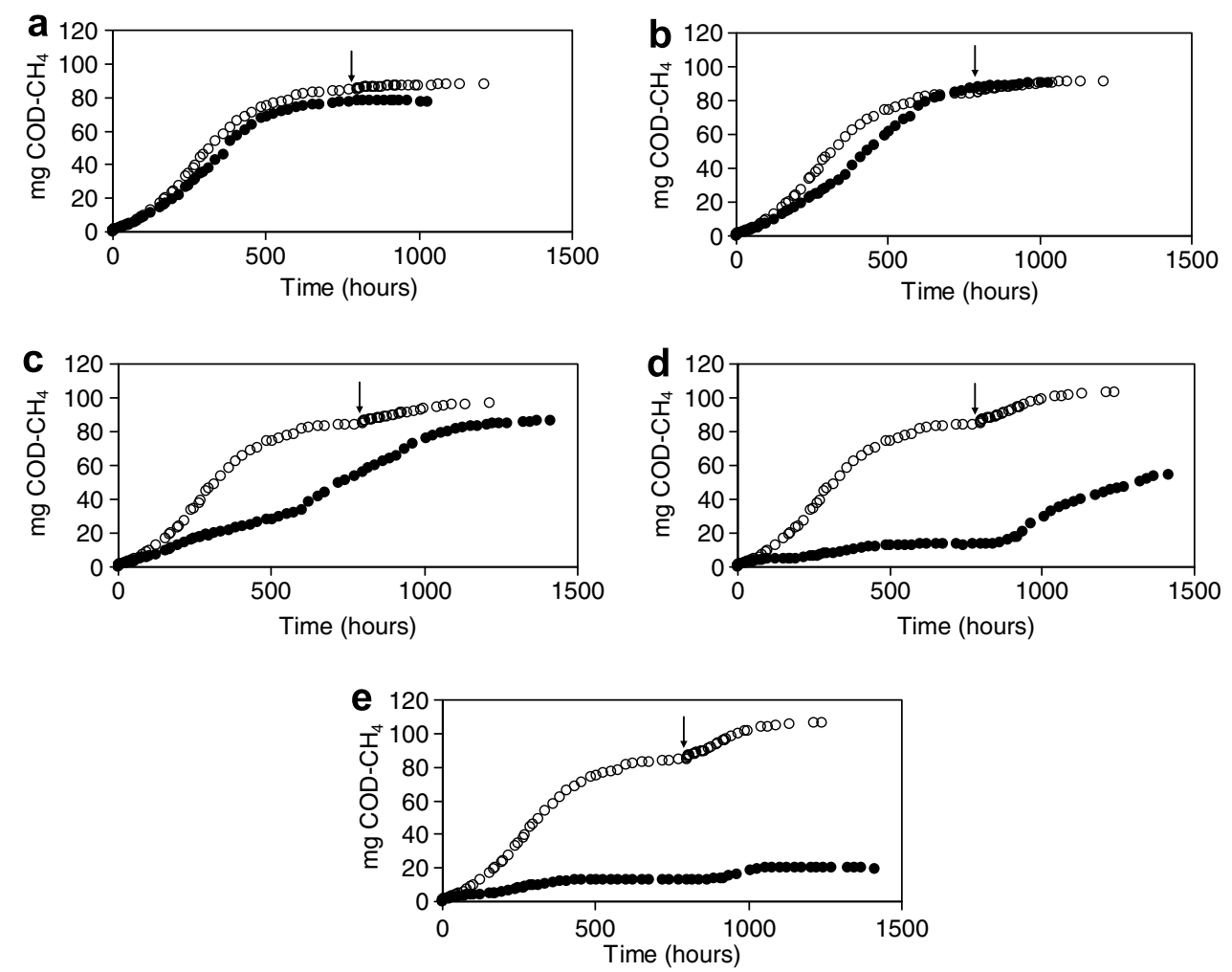

Fig. 2. Methane production during palmitate biodegradation batch experiments exhibited by sludge 2, when palmitate at concentrations of 100 (a), 300 (b), 500 (c), 700 (d) and 900 (e) $\mathrm{mg} \mathrm{L}^{-1}$, was added before (full circles) and after (open circles) allowing the degradation of the biomass-associated LCFA (arrows indicate moment of palmitate addition). Average values are presented and maximum standard deviation was $10 \%$. 
conversion to methane of the biomass-associated LCFA, mainly palmitate. On the other hand, it was observed that the way of LCFA accumulation was different in the two sludges. In sludge 1 , the biomass-associated LCFA were mainly adsorbed and entrapped in the sludge that became "encapsulated" by a LCFA layer, whereas in sludge 2 were mainly aggregated in white precipitate-like spots in between the sludge, which remained "non-encapsulated". Hence, besides the potential inhibitory effect caused by the added LCFA, it is reasonable to expect that, in sludge 1 , the biomass-associated LCFA can create a physical barrier and hinder the transfer of substrates and products (e.g. biogas release), inducing a delay on the initial methane production. In sludge 2, the accumulated LCFA was in a loosely association with the cells ("non-encapsulated"), and thus mass transfer limitations are not expected to occur in a similar extent as in sludge 1.

The different degree of intimate LCFA contact with the biomass is also, likely, related to the difference observed, in terms of initial methane production, in the assays where the biomass-associated LCFA was first let to degrade before a new LCFA addition (open circles curves). For sludge 2, no lag phases were observed preceding the initial methane production during the LCFA degradation, biomass-associated and subsequently added (Fig. 2), whereas for sludge 1 a lag phase of about $500 \mathrm{~h}$ was observed before the onset of methane production from the degradation of the biomass-associated LCFA (when the sludge was "encapsulated") and up to $200 \mathrm{~h}$ from the afterwards added oleate concentrations (Fig. 1). In sludge 1, after depletion of the biomass-associated LCFA, the transport limitation effects caused by the accumulated LCFA can be eliminated, however, sludge microstructure where filaments form an interlinking grid is now "free" to further accumulate the added LCFA, which may induce once more delays on the measured initial methane production (lag phases).

The time course of methane production when acetate and increasing oleate/palmitate concentrations were added to both sludges before and after the degradation of the accumulated LCFA was assessed. This type of assay is usually performed to assess the tolerance of the acetoclastic trophic group to the presence of a given compound that can exert any type of inhibition. When a biodegradable compound is to be assessed, the data interpretation should be careful.

Fig. 3 presents the long-term methane production curves exhibited by sludge 1 during oleate toxicity tests. As shown in Fig. 3a, no initial methane production was observed in the assay performed with the sludge containing biomassassociated LCFA. Only in the blank controls (no added substrate), that corresponded to the degradation of the biomass-associated LCFA, methane was produced after a lag phase of about $500 \mathrm{~h}$, as previously observed in the biodegradation assays (Fig. 1). After degradation of the biomassassociated LCFA (Fig. 3b), methane production due to the degradation of acetate (control) proceeded immediately and the maximum delay on methane production obtained was of about $80 \mathrm{~h}$, when $900 \mathrm{mg} \mathrm{L}^{-1}$ of oleate was added.

Usually the negative effect of a potential toxic compound is expressed as $\mathrm{IC}_{50}$ values, defined as the concentration that causes a $50 \%$ relative activity loss. Before degrading the biomass-associated LCFA, sludge 1 exhibited no initial methanogenic activity with acetate (control) and, therefore, the toxicity index $\left(\mathrm{IC}_{50}\right)$ could not be determined. After depletion of the biomass-associated LCFA, the sludge exhibited a toxicity index $\left(\mathrm{IC}_{50}\right)$ to oleate of $80 \pm 10 \mathrm{mg} \mathrm{L}^{-1}$. A similar $\mathrm{IC}_{50}$ value, i.e. $70 \pm 10 \mathrm{mg} \mathrm{L}^{-1}$, was previously exhibited by the sludge used as inoculum in the pre-contact with oleate/palmitate in the EGSB reactors (Pereira et al., 2005). This suggests that aceticlastic tolerance to oleate was not significantly affected by the intensive and intimate contact with LCFA.

Fig. 4 presents the long-term methane production curves exhibited by sludge 2 (feed with palmitate) during palmitate toxicity tests. This sludge was able to exhibit a considerable initial methane production rate in the control vials, where acetate was added to the sludge containing biomassassociated LCFA (Fig. 4a). However, the presence of acetate (control) was found to induce a delay on the conversion to methane of the biomass-associated LCFA (blank). Furthermore, the initial methane production rate, under these conditions (acetate + biomass-associated LCFA), decreased consistently by increasing the added palmitate concentrations. Since the specific methanogenic
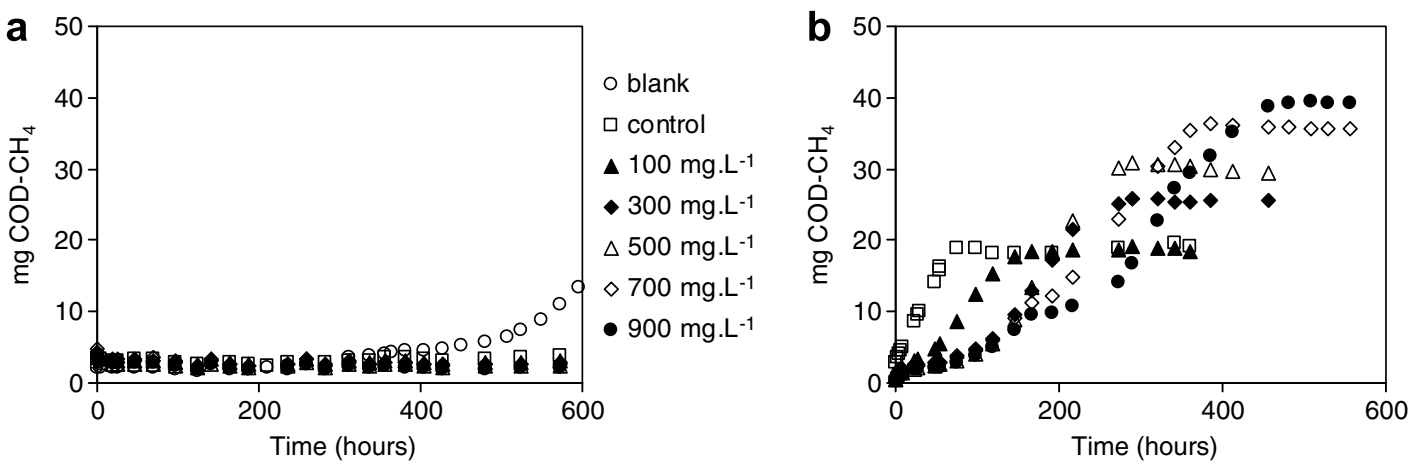

Fig. 3. Long-term methane production curves obtained for sludge 1 (a) before and (b) after allowing the degradation of the biomass-associated LCFA, during oleate toxicity tests. Average values are presented and maximum standard deviation was $10 \%$. 

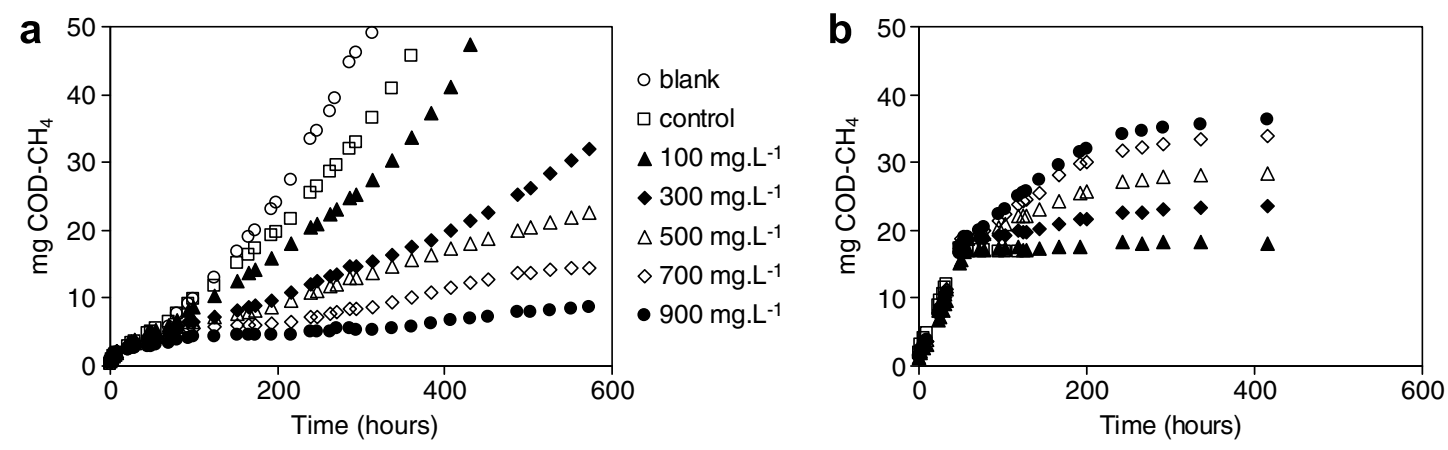

Fig. 4. Long-term methane production curves obtained for sludge 2 (a) before and (b) after allowing the degradation of the biomass-associated LCFA, during palmitate toxicity tests. Average values are presented and maximum standard deviation was $10 \%$.

activity values are, by definition, obtained after discounting the background methane production measured in the blank controls, which correspond to the degradation of the biomass-associated LCFA, the delay caused by the presence of acetate will, thus, result in a null aceticlastic activity value. Consequently, palmitate toxicity index $\left(\mathrm{IC}_{50}\right)$ towards the aceticlastic consortium could not be determined in this case. After degradation of the biomass-associated LCFA, no aceticlastic inhibition was observed in the range of palmitate concentrations tested (Fig. 4b). The methane production curves clearly evidence that the presence of palmitate had no interference on acetate degradation rate, which was preferentially uptake by the consortium. A similar behavior had been show by the sludge before being continuously loaded with palmitate, i.e. the inoculum (Pereira et al., 2005). These results, therefore, evidence that, as found for the sludge 1, for the sludge 2 it is advantageous to allow the degradation of the accumulated LCFA, since, afterwards, the performance of the acetoclastic trophic group is less affected by the presence of LCFA.

The results presented herein evidence the advantages of promoting the degradation of the biomass-associated LCFA, prior to a new LCFA addition, suggesting that a sequence of loading/degradation steps is appropriate to enhance methane production from wastewaters containing these compounds.

Dairy industry produces different products generating wastewaters that differ much in terms of organic strength, to which, besides fats $\left(35-500 \mathrm{mg} \mathrm{L}^{-1}\right)$, lactose $(250$ $\left.930 \mathrm{mg} \mathrm{L}^{-1}\right)$ and proteins $\left(210-560 \mathrm{mg} \mathrm{L}^{-1}\right)$ are primary contributors (Lalman et al., 2004). Oleate and palmitate are the major LCFA present in whole milk processing wastewaters (Hanaki et al., 1981), and thus expected in most dairy wastewaters. Therefore, the anaerobic treatment of a real dairy wastewater rich in fat, through successive pulse feeding, was further assessed.

\subsection{Experiment II: repeated pulse feeding of a dairy effluent in batch assays}

Anaerobic bioconversion to methane of repeated pulses of a dairy wastewater was studied in batch assays. Soluble
COD, VFA and methane production were followed along time, after each pulse, and the data obtained are presented in Fig. 5. Soluble COD removal efficiency achieved after each pulse was always higher than $90 \%$ and its rate improved in each new pulse (Fig. 5b). However, it is clear that in the first pulse most of the COD was not converted to methane. Indeed, the cumulative methane production (expressed as equivalent COD per liter) after the first pulse was much lower than the initial COD fed (Fig. 5a). This fact points out that the substrate probably accumulated onto the sludge, by mechanisms of adsorption, precipitation or entrapment. After the second pulse the maximum cumulative methane production was much more consistent with the initial COD fed and in the third pulse was even higher (Fig. 5a), indicating an efficient conversion to methane of the substrate previously accumulated.

No lag phases were observed, but, after the first pulse the cumulative methane production curve exhibited a diauxic behavior (Fig. 5a), which can be related to the fact that a complex wastewater was fed. It is expected a faster degradation of more easily biodegradable substances, followed by the conversion to methane of a more difficult fraction likely the LCFA. This behavior was not observed after the second and third pulses, which suggests that the anaerobic consortium adapted to the new feed during the first pulse and was capable of its whole conversion to methane without diauxic behavior.

The VFA levels were also significantly different after the first pulse and after the subsequent ones (Fig. 5c). Acetate, that was detected in concentrations up to $600 \mathrm{mg} \mathrm{COD} \mathrm{L}^{-1}$ after the first pulse, did not appear in concentrations higher than $100 \mathrm{mg} \mathrm{COD} \mathrm{L}^{-1}$ in the second one and was consistently below in the third one.

Fig. 6 presents the fractions of adsorbed (or precipitated/entrapped) COD and methane-COD. As previously stated by other authors (Hanaki et al., 1981; Petruy and Lettinga, 1997), adsorption is a very fast process, as suggested by the low soluble COD values observed during the first day after each pulse (Fig. 5a). After adsorption, a significant increase in the methane production was observed, more evidenced after the second and third pulses than in the first one. Again it is possible to notice that in the third pulse some of the methane produced resulted 

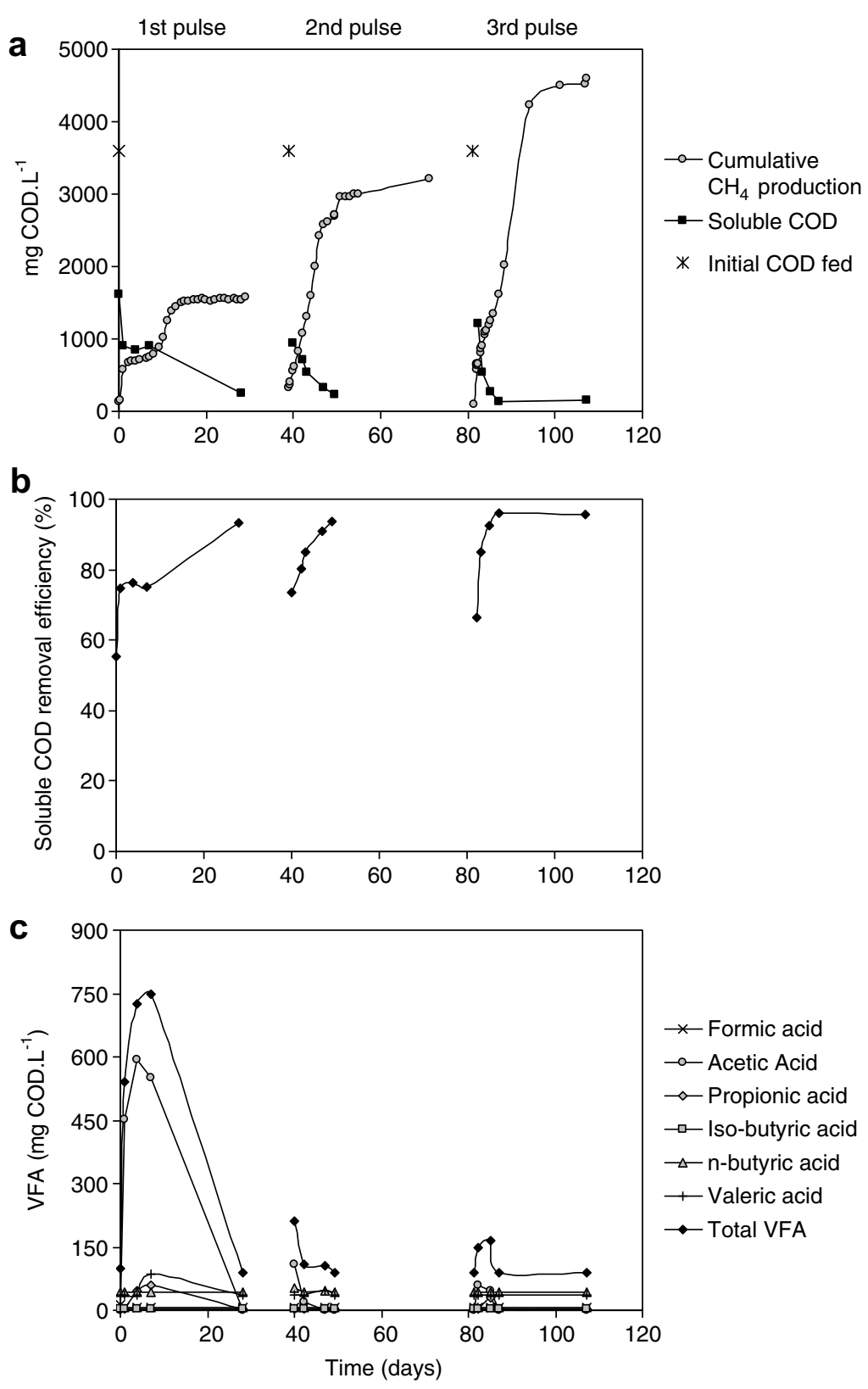

Fig. 5. Performance parameters during the three successive pulses. (a) Cumulative methane production and soluble COD values. (b) Soluble COD removal efficiency. (c) VFA concentration in the medium. Average values are presented and maximum standard deviation was $10 \%$.

from the degradation of substrate accumulated onto the biomass in the previous feeds, leading to a fraction of COD converted to methane higher than $100 \%$. A methane yield of $0.45 \pm 0.01,0.88 \pm 0.02$ and $1.29 \pm 0.08 \mathrm{~g}$ COD$\mathrm{CH}_{4} \mathrm{~g} \mathrm{COD} \mathrm{fed}^{-1}$ was achieved in the first, second and third pulses, respectively.

These results show that anaerobic treatment of a fat rich dairy wastewater is enhanced when repeated pulse feeding is applied. By allowing the substrate to accumulate onto the sludge and be further degraded before subsequent substrate addition, advantage can be taken from the capacity of the anaerobic sludge to fast adsorb LCFA (as well as to accumulate LCFA precipitates or to entrap in the sludge structure) and convert the accumulated LCFA to methane, increasing the obtained methane yield. Furthermore, excessive accumulation of LCFA into the sludge can be prevented and, thus, associated metabolic and physical effects that are behind the decrease on the methane production course during the anaerobic degradation process can be minimized. Considering the present assay, it should be referred that around $38 \%$ of the total substrate added cumulatively to the vials was not converted to methane. This points out the need for further studies involving more pulses in order to assess the optimal strategy concerning the duration and frequency of substrate pulse additions.

When applying high rate anaerobic reactors to treat wastewaters with a high content of lipids/LCFA, the obtained methane yields are generally low, drastically 


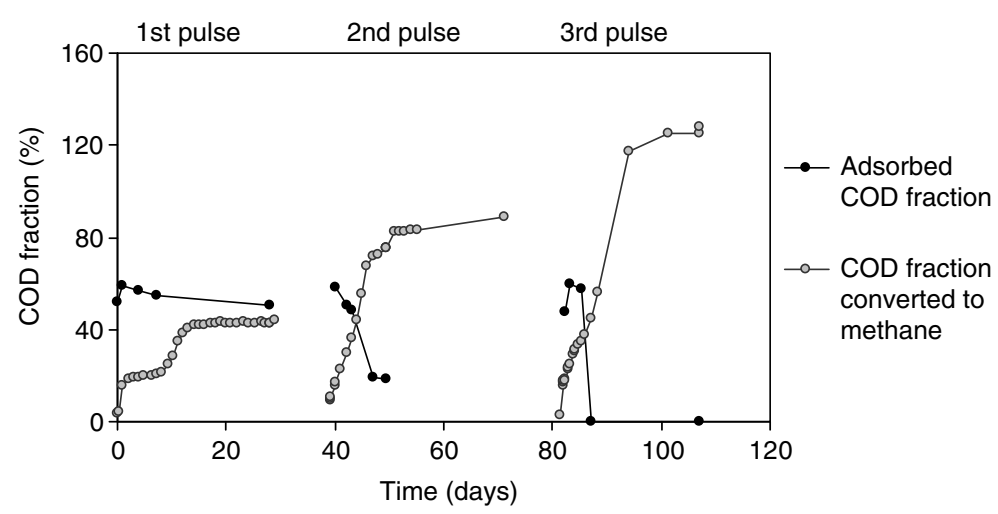

Fig. 6. Fractions of adsorbed COD and COD converted to methane in the three successive pulses.

decreasing throughout the operation time. For instance, when a mixture of long chain fatty acids $(82 \%(\mathrm{w} / \mathrm{w})$ oleate and $18 \%$ palmitate) was fed as sole carbon and energy source to an EGSB reactor, methane conversion ratios attained extremely low values, between $7 \%$ and $15 \%$ (Hwu et al., 1998). Studying the biodegradability of a milk-fat emulsion in a lab-scale EGSB reactor, Petruy and Lettinga (1997) reported that a significant fraction of COD fed was eliminated from the liquid medium by adsorption onto the granular sludge, but it was not biodegraded, since the methanogenesis reached only $22 \%$ of COD fed. Pereira et al. (2002b) operated an EGSB reactor and an anaerobic filter (AF) with an oleic acid-based synthetic effluent. Organic loading rates of 8 and $12 \mathrm{~g} \mathrm{COD} \mathrm{L}^{-1} \mathrm{day}^{-1}$ of oleate as the sole carbon source were achieved in the EGSB and AF, respectively, with good COD removal efficiencies (around $80 \%$ and $70 \%$, respectively), but the methane yield decreased from 280 to $27 \mathrm{~L} \mathrm{CH}_{4} \mathrm{~kg} \mathrm{COD} \mathrm{removed}^{-1}$ in the EGSB and from 362 to $91 \mathrm{~L} \mathrm{CH}_{4} \mathrm{~kg} \mathrm{COD}$ removed $^{-1}$ in the AF. Furthermore, in recent studies performed by Jeganathan et al. (2006), using upflow anaerobic sludge blanket (UASB) reactors to treat a complex oily wastewater from a food industry, it was reported that although approximately $75 \%$ of COD was degraded (which corresponded to the observed biogas yield) for an organic loading rate (OLR) of about $2.5 \mathrm{~kg} \mathrm{COD} \mathrm{m}^{-3} \mathrm{day}^{-1}$, system performance deteriorated sharply at higher loading rates. An increase in loading to $5 \mathrm{~kg} \mathrm{COD} \mathrm{m}^{-3} \mathrm{day}^{-1}$ caused fat, oil, and grease (FOG) accumulation in sludge and increase in foam production which reduced degradation to $40-50 \%$. These authors also reported that accumulation of FOG in the biomass was the critical parameter governing the high-rate anaerobic reactor performance and further suggest the need for periodic reseeding of anaerobic reactor systems treating oily wastes, since the loss of sludge in the bed, due to washout, increased the FOG loading to the biomass and failure occurrence. Sludge flotation and washout due to lipids/LCFA accumulation, are known common problems encountered when using continuous load systems to treat this kind of wastewaters (Sam-Soon et al., 1991;
Hawkes et al., 1995; Hwu, 1997; Pereira et al., 2002b), which can be overcome when excessive accumulation of LCFA into the sludge is prevented by allowing the substrate accumulated onto the sludge to be degraded before subsequence substrate addition, i.e. using pulse feeding. In the present work, the improving performance observed in the recurrent pulses clearly suggests that further research is needed to assess the optimal feeding strategy, being eventually possible that after a start-up in pulses a continuous load may be applied achieving a high methane yield at a high rate.

\section{Conclusions}

When treating anaerobically LCFA based effluents, it is advantageous to apply pulses of substrate, promoting the accumulation of LCFA into the biomass and allowing them to be biodegraded afterwards. LCFA loading/degradation process increased the tolerance of the acetotrophic methanogens to LCFA effect, by reducing significantly the lag phases observed before the onset of methane production. This fact was reinforced when three repeated pulses of a real dairy wastewater rich in fat were conducted in batch assays. COD removal efficiency and maximum cumulative methane production improved in each new pulse, and the VFA levels decreased significantly. The improving performance observed in the recurrent pulses clearly suggests that further research is needed to assess the optimal feeding strategy, being eventually possible that after a pulsed or discontinuous start-up a continuous load of LCFA based effluents may be applied, achieving a high methane yield at a high rate, under steady-state conditions.

\section{Acknowledgements}

The support of Lúcia Neves and Diana Sousa during the experimental work is gratefully acknowledged. This study was partially financed by Fundação para a Ciência e Tecnologia (FCT) and Fundo Social Europeu (FSE), through the Grant SFRH/BPD/14591/2003 given to M. A. Pereira, and the Project POCTI/CTA/46328/2002. 


\section{References}

Amaral, A.L., Pereira, M.A., da Motta, M., Pons, M.-N., Mota, M., Ferreira, E.C., Alves, M.M., 2004. Development of image analysis techniques as a tool to detect and quantify morphological changes in anaerobic sludge: II. Application to a granule deterioration process triggered by contact with oleic acid. Biotechnol. Bioeng. 87, 194-199.

APHA, AWWA, WPCF, 1989. Standard Methods for the Examination of Water and Wastewater, 17th ed. American Public Health Association, Washington, DC.

Arnaiz, C., Buffiere, P., Elmaleh, S., Lebrato, J., Moletta, R., 2003. Anaerobic digestion of dairy wastewater by inverse fluidization: the inverse fluidized bed and the inverse turbulent bed reactors. Environ. Technol. 24, 1431-1443.

Faisal, M., Unno, H., 2001. Kinetic analysis of palm oil mill wastewater treatment by a modified anaerobic baffled reactor. Biochem. Eng. J. 9, 25-31.

Gujer, W., Zehnder, A.J.B., 1983. Conversion processes in anaerobic digestion. Water Sci. Technol. 15, 127-167.

Hanaki, K., Matsuo, T., Nagase, M., 1981. Mechanisms of inhibition caused by long chain fatty acids in anaerobic digestion process. Biotechnol. Bioeng. 23, 1591-1610.

Haridas, A., Suresh, S., Chitra, K.R., Manilal, V.B., 2005. The Buoyan filter bioreactor: a high-rate anaerobic reactor for complex wastewater - process dynamics with dairy effluent. Water Res. 39, 993-1004.

Hawkes, F.R., Donnely, T., Anderson, G.K., 1995. Comparative performance of anaerobic digesters operating on ice-cream wastewater. Water Res. 29, 525-533.

Hwu, C.-S., Tseng, S.K., Yuan, C.Y., Kulik, Z., Lettinga, G., 1998. Biosorption of long-chain fatty acids in UASB treatment process. Water Res. 32, 1571-1579.

Hwu, C.-S., 1997. Enhancing anaerobic treatment of wastewaters containing oleic acid. Ph.D. Thesis, Wageningen Agricultural University, Wageningen, The Netherlands.

Jeganathan, J., Nakhla, G., Bassi, A., 2006. Long-term performance of high-rate anaerobic reactors for the treatment of oily wastewater. Environ. Sci. Technol. 40, 6466-6472.

Kim, S.H., Han, S.K., Shin, H.S., 2004. Two-phase anaerobic treatment system for fat-containing wastewater. J. Chem. Technol. Biotechnol. 79, 63-71.

Lalman, J.A., Komjarova, I., Jing, N., 2004. Lactose fermentation in the presence of C18 fatty acids. J. Chem. Technol. Biotechnol. 79, 12591267.

Li, Y.Y., Sasaki, H., Yamashita, K., Seki, K., Kamigochi, I., 2002. Highrate methane fermentation of lipid-rich food wastes by a high-solids co-digestion process. Water Sci. Technol. 45, 143-150.

Masse, L., Masse, D.I., Kennedy, K.J., Chou, S.P., 2002. Neutral fat hydrolysis and long-chain fatty acid oxidation during anaerobic digestion of slaughterhouse wastewater. Biotechnol. Bioeng. 79, 43-52.
Miranda, L.A.S., Henriques, J.A.P., Monteggia, L.O., 2006. Performance of UASB and DAEB reactors in the anaerobic digestion of synthetic wastewater containing sodium oleate and sodium stereate. Water Sci. Technol. 54, 127-133.

Nielsen, H.B., Ahring, B.K., 2006. Responses of the biogas process to pulses of oleate in reactors treating mixtures of cattle and pig manure. Biotechnol. Bioeng. 95, 96-105.

Núnez, L.A., Martínez, B., 1999. Anaerobic treatment of slaughterhouse wastewater in an Expanded Granular Sludge Bed (EGSB) reactor. Water Sci. Technol. 40, 99-106.

Pereira, M.A., Mota, M., Alves, M.M., 2002b. Operation of an anaerobic filter and EGSB reactor for the treatment of an oleic acid-based effluent: influence of inoculum quality. Proc. Biochem. 37, 1025-1031.

Pereira, M.A., Pires, O.C., Mota, M., Alves, M.M., 2002a. Anaerobic degradation of oleic acid by suspended and granular sludge: identification of palmitic acid as a key intermediate. Water Sci. Technol. 45, 139-144.

Pereira, M.A., Pires, O.C., Mota, M., Alves, M.M., 2005. Anaerobic biodegradation of oleic and palmitic acids: evidence of mass transfer limitations caused by the accumulation of LCFA onto the anaerobic sludge. Biotechnol. Bioeng. 92, 15-23.

Pereira, M.A., Sousa, D.Z., Mota, M., Alves, M.M., 2004. Mineralization of LCFA associated to anaerobic sludge: kinetics, transport limitations, enhancement of methanogenic activity and effect of VFA. Biotechnol. Bioeng. 88, 502-511.

Petruy, R., Lettinga, G., 1997. Digestion of a milk-fat emulsion. Biores. Technol. 61, 141-149.

Quéméneur, M., Marty, Y., 1994. Fatty acids and sterols in domestic wastewaters. Water Res. 28, 1217-1226.

Saatci, Y., Arslan, E.I., Konar, V., 2003. Removal of total lipids and fatty acids from sunflower oil factory effluent by UASB reactor. Biores. Technol. 87, 269-272.

Sam-Soon, P., Loewenthal, R.E., Wentzel, M.C., Marais, G.V.R., 1991. A long chain fatty acid, oleate, as sole substrate in upflow anaerobic sludge bed (UASB) reactor systems. Water SA 17, 31-36.

Sousa, D.Z., 2007. Ecology and physiology of anaerobic microbial communities that degrade Long Chain Fatty Acids, $\mathrm{PhD}$ Thesis, University of Minho, Portugal. <http://repositorium.sdum.uminho.pt/ handle/1822/6287>.

Stryer, L., 1995. Fatty acid metabolism, fourth ed.. Biochemistry W.H. Freeman and Co., New York, USA, pp. 603-628.

Torkian, A., Eqbali, A., Hashemian, S.J., 2003. The effect of organic loading rate on the performance of UASB reactor treating slaughterhouse effluent. Res. Conser. Recycle 40, 1-11.

Viswanathan, C.V., Meera Bai, B., Pillai, S.C., 1962. Fatty matter in aerobic and anaerobic sewage sludges. J. Water Pollut. Control Fed. 34, 189-194.

Yang, J., Speece, R.E., 1986. The effects of chloroform toxicity on methane fermentation. Water Res. 20, 1273-1279. 